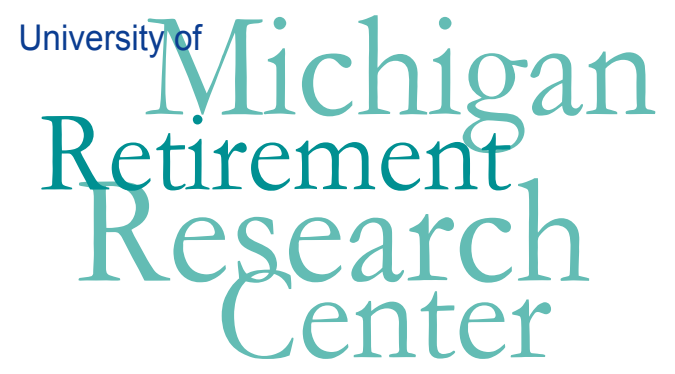

Working Paper

WP 2003-060

\title{
The Demand for Guarantees in Social Security Personal Retirement Accounts
}

Olivia S. Mitchell and Alexander Muermann

\begin{tabular}{|l|l|}
\hline $\mathrm{M}$ & $\mathrm{R}$ \\
\hline $\mathrm{R}$ & $\mathrm{C}$ \\
\hline
\end{tabular}$\quad$ Project \#: UM03-05 


\title{
"The Demand for Guarantees in Social Security Personal Retirement Accounts"
}

\author{
Olivia S. Mitchell \\ The Wharton School of the University of Pennsylvania \\ Alexander Muermann \\ The Wharton School of the University of Pennsylvania
}

October 2003

\author{
Michigan Retirement Research Center \\ University of Michigan \\ P.O. Box 1248 \\ Ann Arbor, MI 48104
}

\section{Acknowledgements}

This work was supported by a grant from the Social Security Administration through the Michigan Retirement Research Center (Grant \# 10-P-98358-5). The opinions and conclusions are solely those of the authors and should not be considered as representing the opinions or policy of the Social Security Administration or any agency of the Federal Government.

\section{Regents of the University of Michigan}

David A. Brandon, Ann Arbor; Laurence B. Deitch, Bingham Farms; Olivia P. Maynard, Goodrich; Rebecca McGowan, Ann Arbor; Andrea Fischer Newman, Ann Arbor; Andrew C. Richner, Grosse Pointe Park; S. Martin Taylor, Gross Pointe Farms; Katherine E. White, Ann Arbor; Mary Sue Coleman, ex officio 


\title{
The Demand for Guarantees in Social Security Personal Retirement Accounts
}

Olivia S. Mitchell

Alexander Muermann

\begin{abstract}
This project evaluates how workers might invest their Personal Retirement Account (PRA) funds between safe and risky assets, depending on whether they are offered a rate of return guarantee on the risky asset. We focus on how asset allocation decisions might differ depending on participants' attitudes about risk and regret. If, for example, the return on the risky asset turns out to be very high when a worker retires, he might regret not having allocated a large enough portion of his contributions to the risky asset. On the contrary, if the stock market does poorly, the retiree might regret having invested at all in that asset. We show that anticipated disutility from regret can have a potent effect on investment choices in a PRA. If there is no guarantee, regret induces investors to move away from extreme decisions: that is, investors who take regret into account hold less stock if the risk premium is high, but more stocks if the risk premium is low. Further, a rate of return guarantee provided at no cost to the plan participant induces him to hold more stocks, with or without regret. We also show that, with or without regret, investors' willingness to pay for a guarantee rises with the level of the guaranteed return. This research could be informative regarding the potential profitability of the guaranteed pension business, which would help determine whether a government subsidy would be required to bring these products to market.
\end{abstract}

\section{Authors' Acknowledgements}

Muermann is Assistant Professor of Insurance and Risk Management at the Wharton School, University of Pennsylvania. Mitchell is Research Associate, NBER, and International Foundation of Employee Benefit Plans Professor of Insurance and Risk Management, and Executive Director of the Pension Research Council and the Boettener Center for Pensions and Retirement Research, at the Wharton School, University of Pennsylvania. This research was carried out with the assistance of Jacqueline Volkman, a Doctoral student of Insurance and Risk Management at the Wharton School, University of Pennsylvania. Funding for this research was provided by the Social Security Administration through a grant to the Michigan Retirement Research Center, and by the Pension Research Council. For helpful suggestions we thank Marie-Eve Lachance but we retain full responsibility for the views contained herein. (C) 2003 Muermann, and Mitchell. 


\section{Introduction}

The last two decades have wrought unprecedented change in the form and structure of pensions around the world. In the past, many large corporations traditionally offered defined benefit (DB) plans where the plan sponsor promised workers a specified annuity benefit for the length of the retirement period. In such plans, the employer took on asset management responsibility and paid benefits according to pre-set formulas. Over time, however, many of these DB plans were converted into defined contribution (DC) pensions, where employees rather than their employers would now have to decide how much to save and what to invest in. The United States is a case in point, where there are now more DC plans, and more DC-covered workers, than DB plans and covered workers. The DC movement has also spread to the public sector, and recently the US President has proposed that the Social Security system be adjusted to include a DC component (Cogan and Mitchell, 2003).

Though the popularity of the DC model continues to grow, capital market volatility of late has redirected attention to the types of risks confronting DC plan participants. Some analysts have argued that employee protection requires controlling DC asset allocation, forcing participants to hold mainly corporate and government securities (Palacios, forthcoming). Others have suggested that guarantees might be developed for investors with personal retirement accounts (PRAs), on the notion that plan participants would like investment products that would protect them against down-side fluctuations in their assets (Lachance and Mitchell, forthcoming). Indeed, Germany and Japan have recently mandated that participants in DC pensions be promised a principal-guaranteed account at retirement, on the grounds that this will make PRAs more attractive to participants who are not particularly financially sophisticated (Maurer and Schlag, forthcoming).

Of course, DC plan guarantees are not free, so it is important to assess how consumers would adjust their investment portfolios if they were provided. Next, it would be useful to know how participants would value guarantees in PRAs. Our analysis takes into account the possibility that investors may be influenced by the prospect of regret. If, for example, the return on the risky asset turns out to be very high when the worker retires, he may 
regret not having allocated a large enough portion of his contributions to the risky asset. On the contrary, if the stock market does poorly, the retiree might regret having invested at all in that asset. This anticipated disutility from regret could be particularly influential in the context of contributions to a PRA, since most retirement plan participants appear to select an initial asset allocation when they join the plan but do not actively manage their retirement accounts thereafter. ${ }^{1}$

In what follows, we first evaluate the impact of regret on the decision to allocate one's retirement account between a risk-free and a risky asset. We then examine how participants adjust their optimal portfolio allocations if they are offered a guarantee on the risky asset's return. Last, we analyze the impact of regret aversion on the participant's willingness to pay (WTP) for the guarantee.

Our results show that, without a guarantee, regret moves investors' decisions away from the extremes. That is, investors who take regret into account hold more stock if the risk premium is low, but less stock if the risk premium is high. This result may help explain the equity premium puzzle. Further, a rate of return guarantee provided at no cost to the plan participant induces him to hold more stock, with or without regret. At high risk premiums, the guarantee therefore induces decisions by regret-averse investors that are close to the ones of risk-averse investors. On the contrary, at low risk premiums, guarantees move regretaverse investors even further away from investing all in bonds. We also show that, with or without regret, investors' WTP for a guarantee rises with the level of the guaranteed return.

\section{Prior Studies}

A range of pension guarantee mechanisms might be contemplated for PRAs, though typically they take the form of either a rate of return guarantee or a minimum benefit guarantee. In the present paper, we focus on the former structure, wherein the pension manager commits to return to the worker his or her contributions plus some stipulated

\footnotetext{
${ }^{1}$ Agnew et al (2003), in a study of 401k plan participants, report that the vast majority (87 percent) of participants had no annual trades; over a four year period, only a single trade took place per participant. Similarly, Ameriks and Zeldes (2000) show that almost half of all TIAA-CREF participants made no changes in their asset allocations at all during the decade 1987-96.
} 
rate of return. A variation on this would, of course, be a principal guarantee, which is simply equivalent to guaranteeing a nominal rate of return of zero percent. This latter approach has been adopted in DC plans for both Germany and Japan. By contrast, Feldstein and Samwick (2001) have suggested a more generous alternative for the US, namely a real principal guarantee, and a more generous plan still might offer some positive real return. For example, employees might seek a plan that paid back contributions plus the 10-year Treasury bond return.

Naturally, as prior studies have shown, the cost of providing such a guarantee will depend in part on key design features. First, it matters how often the promise must be kept. For example, it might be sufficient to structure the program so that the minimum return is evaluated only at the worker's retirement date. Alternatively, a more frequent minimum return bar could be set, as in Chile, where pension plans must meet an annual threshold, or in Colombia, where three-year periods are used (Pennachi, 1999; Fischer, 1999).

An additional design factor shaping the cost of the pension guarantee has to do with how much investment risk may be borne by the investor in the PRA. Participants could make the guarantee more valuable, and hence costlier, if they have the chance to invest in riskier assets in their PRA portfolios. This moral hazard problem has been recognized by Bodie and Merton (1993) and Smetters (2002), among others, and it has led many countries to impose portfolio restrictions on investors' asset allocations in defined contribution plans. For instance, Mexico until recently mandated that participants had to hold an all-bond portfolio, and Chile initially required the same. Alternatively, governments may want to offer workers in PRAs some protection from market fluctuations without mandating a risk-free portfolio. This can be accomplished by providing a guaranteed return on the risky asset. Our goal is to examine investment behavior in PRA plans in light of rate of return guarantees, introducing the notion of regret aversion in that context.

\section{The Impact of Regret on Portfolio Allocation}

In this section, we examine investment behavior in a PRA setting. We start with the standard 
portfolio problem of risk-averse investor, and then we compare his optimal portfolio allocation with the optimum selected by a regret-averse investor.

\subsection{Risk-Averse Investor}

Suppose an investor has initial wealth $w_{0}$ which he can allocate between a risky and risk-free asset. The return of the risky asset is given by a random variable $R$ which is distributed according to some cumulative distribution function $F$ whereas the risk-free asset yields a deterministic return $r_{f}$. We assume that the investor's preferences can be characterized by a utility function $u(\cdot)$ with $u^{\prime}>0$ and $u^{\prime \prime}<0$. In other words, he allocates his wealth between the two assets to maximize his expected utility of final wealth. The optimal fraction $\alpha^{*}$ invested in the risky asset is thus determined by the following maximization problem

$$
\begin{aligned}
& \max _{\alpha \in[0,1]} E\left[u\left(w_{0}\left(\alpha(1+R)+(1-\alpha)\left(1+r_{f}\right)\right)\right)\right] \\
= & E\left[u\left(w_{0}\left(1+\alpha R+(1-\alpha) r_{f}\right)\right)\right] .
\end{aligned}
$$

In other words, the optimal asset mix in the PRA is a function of his initial wealth level, the size of the risk premium, and preferences. This is the standard portfolio problem and the following proposition states the well-known result that a risk-averse investor invests a positive fraction of his wealth in the risky asset as long as its expected return exceeds the risk-free rate of return (see e.g. Chapter 4, Gollier, 2001).

Proposition 1 If $E[R]-r_{f} \leq 0$ then the investor allocates all his wealth to the risk-free asset, i.e. $\alpha^{*}=0$. If $E[R]-r_{f} \geq \frac{\operatorname{Cov}\left(-R, u^{\prime}\left(w_{0}(1+R)\right)\right)}{E\left[u^{\prime}\left(w_{0}(1+R)\right)\right]}$ then the investor allocates all his wealth to the risky asset, i.e. $\alpha^{*}=1$.

Proof. Let $w(\alpha)=w_{0}\left(1+\alpha R+(1-\alpha) r_{f}\right)$ denote the final level of wealth as a function of fraction $\alpha$ invested into the risky asset. The first- and second-order conditions of the 
investor's optimization problem (1) are

$$
\frac{d E[u(w(\alpha))]}{d \alpha}=E\left[w_{0}\left(R-r_{f}\right) u^{\prime}(w(\alpha))\right]=0
$$

and

$$
\frac{d^{2} E[u(w(\alpha))]}{d \alpha^{2}}=E\left[w_{0}^{2}\left(R-r_{f}\right)^{2} u^{\prime \prime}(w(\alpha))\right]<0
$$

As expected utility is a strictly concave function in $\alpha$ any solution $\alpha^{*}(0,0)$ of $(2)$ will determine the unique global maximum. Evaluating the first derivative at $\alpha=0$ and $\alpha=1$ will determine conditions under which those corner solutions are obtained.

$$
\begin{aligned}
\left.\frac{d E[u(w(\alpha))]}{d \alpha}\right|_{\alpha=0} & =E\left[w_{0}\left(R-r_{f}\right) u^{\prime}\left(w_{0}\left(1+r_{f}\right)\right)\right] \\
& =w_{0} u^{\prime}\left(w_{0}\left(1+r_{f}\right)\right)\left(E[R]-r_{f}\right) .
\end{aligned}
$$

On the other hand, if $E[R] \leq r_{f}$ then $\left.\frac{d E[u(w(\alpha))]}{d \alpha}\right|_{\alpha=0} \leq 0$, and concavity implies the corner solution $\alpha^{*}=0$. This is because

$$
\begin{aligned}
\left.\frac{d E[u(w(\alpha))]}{d \alpha}\right|_{\alpha=1} & =E\left[w_{0}\left(R-r_{f}\right) u^{\prime}\left(w_{0}(1+R)\right)\right] \\
& =w_{0}\left(\operatorname{Cov}\left(R, u^{\prime}\left(w_{0}(1+R)\right)\right)+\left(E[R]-r_{f}\right) E\left[u^{\prime}\left(w_{0}(1+R)\right)\right]\right) .
\end{aligned}
$$

If

$$
r_{f} \leq E[R]-\frac{\operatorname{Cov}\left(-R, u^{\prime}\left(w_{0}(1+R)\right)\right)}{E\left[u^{\prime}\left(w_{0}(1+R)\right)\right]}
$$

where $\operatorname{Cov}\left(-R, u^{\prime}\left(w_{0}(1+R)\right)\right)>0$ then $\left.\frac{d E[u(w(\alpha))]}{d \alpha}\right|_{\alpha=1} \geq 0$ and concavity implies the corner solution $\alpha^{*}=1$.

What this shows is that without a guarantee, the risk-averse investor holds all bonds when the risk premium is nonpositive, but all stock when it is sufficiently high. 


\section{$2.2 \quad$ Regret-Averse Investor}

Now suppose an investor takes into account the fact that he may regret having made an investment decision that proved to be suboptimal ex-post. For example, if the return on the risky asset turns out to be very high, the investor might regret not having allocated his total wealth to the risky asset. And in the contrary case, if the return of the risky asset turns out to be very low or negative, the investor might regret having allocated any wealth to the risky asset at all. To examine the impact of regret on the participant's ex-ante allocation of wealth and how it influences his demand for a guarantee, we follow the approach of Braun and Muermann (2003) to pose the investor's preferences as a two-attribute Bernoulli utility function

$$
u_{k}(w)=u(w)-k \cdot g\left(u\left(w^{\max }\right)-u(w)\right) .
$$

Here $w^{\max }$ is the ex-post optimal level of final wealth, i.e. the level of wealth that results from the optimal ex-ante allocation had the investor known the realized return of the risky asset. The first attribute accounts for risk aversion and is characterized by the investor's utility function $u(\cdot)$ with $u^{\prime}>0$ and $u^{\prime \prime}<0$. The second attribute relates to the fact that the investor is regret-averse. The function $g(\cdot)$ measures the amount of regret that the investor experiences, which depends on the difference between the value he assigns to the ex-post optimal level of wealth $w^{\max }$ that he could have achieved, and the value that he assigns to his actual final level of wealth $w . k>0$ measures the importance of the second attribute "regret" relative to the traditional first attribute expressive of risk aversion. We assume that $g(\cdot)$ is increasing and strictly convex, i.e. $g^{\prime}>0$ and $g^{\prime \prime}>0$. For $k=0$, the investor would simply be a traditional expected utility maximizer, i.e. $u_{0}(w)=u(w)$.

To determine the ex-post optimal level of final wealth $w^{\max }$ for this investor, we must distinguish cases when the risky asset's realized return $r \geq r_{f}$, and also when $r<r_{f}$. In the first case, the regret-averse investor would have wanted to invest all wealth in the risky asset, whereas in the second case it would have been optimal to invest all wealth in the risk-free 
asset. Therefore

$$
w^{\max }=\left\{\begin{array}{ccc}
w_{0}(1+r) & & r \geq r_{f} \\
w_{0}\left(1+r_{f}\right) & & r<r_{f}
\end{array} .\right.
$$

We now compare how anticipation of regret influences the investor's optimal asset allocation. Let $\alpha_{k}^{*}$ denote the optimal fraction invested in the risky asset by an investor with regret parameter $k \geq 0$ with $\alpha_{0}^{*}=\alpha^{*}$. The following proposition shows that a regret-averse investor will always "hedge away from the extremes". In other words, compared to a traditional risk-averse investor, he will select a riskier portfolio allocation if the risk premium is low, and a more moderate portfolio allocation if the risk premium is high.

Proposition 2 If $E[R]-r_{f}=0$ then $\alpha_{k}^{*}>0$ for all $k>0$ whereas $\alpha_{0}^{*}=0$. If $E[R]-r_{f}=$ $\frac{\operatorname{Cov}\left(-R, u^{\prime}\left(w_{0}(1+R)\right)\right)}{E\left[u^{\prime}\left(w_{0}(1+R)\right)\right]}$ then $\alpha_{k}^{*}<1$ for all $k>0$ whereas $\alpha_{0}^{*}=1$.

Proof. The investor's optimization program is

$$
\begin{aligned}
& \max _{\alpha \in[0,1]} E\left[u_{k}(w(\alpha))\right] \\
= & E\left[u(w(\alpha))-k \cdot g\left(u\left(w^{\max }\right)-u(w(\alpha))\right)\right],
\end{aligned}
$$

where $w(\alpha)=w_{0}\left(1+\alpha R+(1-\alpha) r_{f}\right)$ and $w^{\max }=w_{0}\left(1+\max \left(r, r_{f}\right)\right)$ denote the investor's final level and ex-post optimal of wealth. The first- and second-order conditions for (4) are

$$
\frac{d E\left[u_{k}(w(\alpha))\right]}{d \alpha}=E\left[w_{0}\left(R-r_{f}\right) u^{\prime}(w(\alpha))\left(1+k g^{\prime}\left(u\left(w^{\max }\right)-u(w(\alpha))\right)\right)\right]=0
$$


and

$$
\begin{aligned}
\frac{d^{2} E\left[u_{k}(w(\alpha))\right]}{d \alpha^{2}}= & E\left[w_{0}^{2}\left(R-r_{f}\right)^{2} u^{\prime \prime}(w(\alpha))\left(1+k g^{\prime}\left(u\left(w^{\max }\right)-u(w(\alpha))\right)\right)\right] \\
& -E\left[w_{0}^{2}\left(R-r_{f}\right)^{2} k u^{\prime 2}(w(\alpha)) g^{\prime \prime}\left(u\left(w^{\max }\right)-u(w(\alpha))\right)\right]
\end{aligned}
$$

$<0$.

As $E\left[u_{k}(w(\alpha))\right]$ is strictly concave in $\alpha$, any solution of (5) determines the unique global maximum. Suppose $E[R]=r_{f}$. Evaluating the first derivative at $\alpha=0$ yields

$$
\begin{aligned}
\left.\frac{d E\left[u_{k}(w(\alpha))\right]}{d \alpha}\right|_{\alpha=0} & =w_{0} u^{\prime}\left(w_{0}\left(1+r_{f}\right)\right) E\left[\left(R-r_{f}\right)\left(1+k g^{\prime}\left(u\left(w^{\max }\right)-u\left(w_{0}\left(1+r_{f}\right)\right)\right)\right)\right] \\
& =w_{0} u^{\prime}\left(w_{0}\left(1+r_{f}\right)\right) k E\left[\left(R-r_{f}\right) g^{\prime}\left(u\left(w^{\max }\right)-u\left(w_{0}\left(1+r_{f}\right)\right)\right)\right] \\
& >w_{0} u^{\prime}\left(w_{0}\left(1+r_{f}\right)\right) k g^{\prime}(0)\left(E[R]-r_{f}\right) \\
& =0
\end{aligned}
$$

where the FOC (2) is applied to the second equality. The optimal fraction invested in the risky asset is thus strictly positive, i.e. $\alpha_{k}^{*}>0$ for all $k>0$. Now suppose $E[R]-$ $r_{f}=\frac{\operatorname{Cov}\left(-R, u^{\prime}\left(w_{0}(1+R)\right)\right)}{E\left[u^{\prime}\left(w_{0}(1+R)\right)\right]}$. Evaluating the first derivative at $\alpha=1$ yields

$$
\begin{aligned}
\left.\frac{d E\left[u_{k}(w(\alpha))\right]}{d \alpha}\right|_{\alpha=1} & =E\left[w_{0}\left(R-r_{f}\right) u^{\prime}\left(w_{0}(1+R)\right)\left(1+k g^{\prime}\left(u\left(w^{\max }\right)-u\left(w_{0}(1+R)\right)\right)\right)\right] \\
& =k \cdot E\left[w_{0}\left(R-r_{f}\right) u^{\prime}\left(w_{0}(1+R)\right) g^{\prime}\left(u\left(w^{\max }\right)-u\left(w_{0}(1+R)\right)\right)\right]
\end{aligned}
$$

where we applied the FOC (2). For realizations of the risky asset's return $r \geq r_{f}, w^{\max }=$ $w_{0}(1+R)$ and thus $g^{\prime}\left(u\left(w^{\max }\right)-u\left(w_{0}(1+R)\right)\right)=g^{\prime}(0)$. For realizations $r<r_{f}, w^{\max }=$ 
$w_{0}\left(1+r_{f}\right)$ and thus $g^{\prime}\left(u\left(w^{\max }\right)-u\left(w_{0}(1+R)\right)\right)>g^{\prime}(0)$. Therefore

$$
\begin{aligned}
\left.\frac{d E\left[u_{k}(w(\alpha))\right]}{d \alpha}\right|_{\alpha=1} & <k w_{0} g^{\prime}(0) E\left[\left(R-r_{f}\right) u^{\prime}\left(w_{0}(1+R)\right)\right] \\
& =0
\end{aligned}
$$

as $E[R]-r_{f}=\frac{\operatorname{Cov}\left(-R, u^{\prime}\left(w_{0}(1+R)\right)\right)}{E\left[u^{\prime}\left(w_{0}(1+R)\right)\right]}$. Consequently, it is not optimal for the regret-averse investor to hold all of his initial wealth in the risky asset (i.e. $\alpha_{k}^{*}<1$ for all $k>0$ ).

This may be explained intuitively by noting that taking an extreme position, e.g. all bonds, exposes the investor to the possibility of facing extreme regret if stocks do well. By avoiding all bonds, the worker will feel less regret if stocks do well but, in return, he will feel some regret if they do poorly. Convexity of $g$, however, leads to suboptimality of extreme decisions.

In the following proposition, we show that higher regret amplifies the effect of "hedging one's bet".

Proposition 3 If the investor weights regret more strongly relative to risk aversion - as measured by $k$ - then for $E[R]-r_{f} \leq 0$ he invests more in the risky asset, whereas for $E[R]-r_{f} \geq \frac{\operatorname{Cov}\left(-R, u^{\prime}\left(w_{0}(1+R)\right)\right)}{E\left[u^{\prime}\left(w_{0}(1+R)\right)\right]}$ he invests less in the risky asset, i.e.

$$
\begin{aligned}
& \frac{\partial \alpha_{k}^{*}}{\partial k}>0 \quad \text { if } \quad E[R]-r_{f} \leq 0 \\
& \frac{\partial \alpha_{k}^{*}}{\partial k}<0 \quad \text { if } \quad E[R]-r_{f} \geq \frac{\operatorname{Cov}\left(-R, u^{\prime}\left(w_{0}(1+R)\right)\right)}{E\left[u^{\prime}\left(w_{0}(1+R)\right)\right]}
\end{aligned} .
$$

Proof. Taking the total differential of the first-order condition (5) with respect to $\alpha$ and $k$ leads to

$$
\frac{\partial^{2} E\left[u_{k}(w(\alpha))\right]}{\partial \alpha^{2}} \cdot d \alpha+\frac{\partial^{2} E\left[u_{k}(w(\alpha))\right]}{\partial \alpha \partial k} \cdot d k=0
$$

and therefore

$$
\frac{\partial \alpha_{k}^{*}}{\partial k}=-\frac{\left.\frac{\partial^{2} E\left[u_{k}(w(\alpha))\right]}{\partial \alpha \partial k}\right|_{\alpha=\alpha_{k}^{*}}}{\left.\frac{\partial^{2} E\left[u_{k}(w(\alpha))\right]}{\partial \alpha^{2}}\right|_{\alpha=\alpha_{k}^{*}}} .
$$


$\left.\operatorname{As} \frac{\partial^{2} E\left[u_{k}(w(\alpha))\right]}{\partial \alpha^{2}}\right|_{\alpha=\alpha_{k}^{*}}<0$

$$
\operatorname{sign}\left(\frac{\partial \alpha_{k}^{*}}{\partial k}\right)=\operatorname{sign}\left(\left.\frac{\partial^{2} E\left[u_{k}(w(\alpha))\right]}{\partial \alpha \partial k}\right|_{\alpha=\alpha_{k}^{*}}\right) \text {. }
$$

The cross-partial derivative equals

$$
\left.\frac{\partial^{2} E\left[u_{k}(w(\alpha))\right]}{\partial \alpha \partial k}\right|_{\alpha=\alpha_{k}^{*}}=E\left[w_{0}\left(R-r_{f}\right) u^{\prime}\left(w\left(\alpha_{k}^{*}\right)\right) g^{\prime}\left(u\left(w^{\max }\right)-u\left(w\left(\alpha_{k}^{*}\right)\right)\right)\right] .
$$

From the FOC (5) we imply

$$
k E\left[w_{0}\left(R-r_{f}\right) u^{\prime}\left(w\left(\alpha_{k}^{*}\right)\right) g^{\prime}\left(u\left(w^{\max }\right)-u\left(w\left(\alpha_{k}^{*}\right)\right)\right)\right]=-E\left[w_{0}\left(R-r_{f}\right) u^{\prime}\left(w\left(\alpha_{k}^{*}\right)\right)\right]
$$

and therefore

$$
\operatorname{sign}\left(\left.\frac{\partial^{2} E\left[u_{k}(w(\alpha))\right]}{\partial \alpha \partial k}\right|_{\alpha=\alpha_{k}^{*}}\right)=-\operatorname{sign}\left(E\left[w_{0}\left(R-r_{f}\right) u^{\prime}\left(w\left(\alpha_{k}^{*}\right)\right)\right]\right) .
$$

If $r_{f} \geq E[R]$, we know that $E\left[w_{0}\left(R-r_{f}\right) u^{\prime}(w(0))\right]=0$ from the FOC (2) and $\alpha_{k}^{*}>0$ from Proposition 2. Concavity of $u(\cdot)$ then implies that $E\left[w_{0}\left(R-r_{f}\right) u^{\prime}\left(w\left(\alpha_{k}^{*}\right)\right)\right]<0$ and thus $\operatorname{sign}\left(\left.\frac{\partial^{2} E\left[u_{k}(w(\alpha))\right]}{\partial \alpha \partial k}\right|_{\alpha=\alpha_{k}^{*}}\right)>0$. (7) shows that $\frac{\partial \alpha_{k}^{*}}{\partial k}>0$. Analogously, if $E[R]-r_{f} \geq \frac{\operatorname{Cov}\left(-R, u^{\prime}\left(w_{0}(1+R)\right)\right)}{E\left[u^{\prime}\left(w_{0}(1+R)\right)\right]}$, we know that $E\left[w_{0}\left(R-r_{f}\right) u^{\prime}(w(1))\right]=0$ from the FOC (2) and $\alpha_{k}^{*}<1$ from Proposition 2. Concavity of $u(\cdot)$ then implies that $E\left[w_{0}\left(R-r_{f}\right) u^{\prime}\left(w\left(\alpha_{k}^{*}\right)\right)\right]>0$ and thus $\operatorname{sign}\left(\left.\frac{\partial^{2} E\left[u_{k}(w(\alpha))\right]}{\partial \alpha \partial k}\right|_{\alpha=\alpha_{k}^{*}}\right)<$ 0. (7) shows that $\frac{\partial \alpha_{k}^{*}}{\partial k}<0$.

In other words, the more regret-averse the participant, the more likely he will be to hold stock in his portfolio as long as the risk premium is low. Conversely, he will hold less stock if the risk premium is high.

In the next proposition, we show that there exists a risk-free rate of return and therefore a risk premium at which regret has no impact on the investor's optimal fraction invested in the risky asset. That is, a regret-averse investor holds the same portfolio allocation as a risk-averse investor at that risk premium. 
Proposition 4 There exists $\widehat{r_{f}}$ such that $0<E[R]-\widehat{r_{f}}<\frac{\operatorname{Cov}\left(-R, u^{\prime}\left(w_{0}(1+R)\right)\right)}{E\left[u^{\prime}\left(w_{0}(1+R)\right)\right]}$ and $\alpha_{k}^{*}=\alpha_{0}^{*}$ for all $k>0$.

Proof. For any fixed $k>0$ we have

$$
\begin{array}{lll}
\alpha_{k}^{*}>0 \text { and } \alpha_{0}^{*}=0 & \text { if } \quad E[R]-r_{f}=0 \\
\alpha_{k}^{*}<1 \text { and } \alpha_{0}^{*}=1 \quad \text { if } \quad E[R]-r_{f}=\frac{\operatorname{Cov}\left(-R, u^{\prime}\left(w_{0}(1+R)\right)\right)}{E\left[u^{\prime}\left(w_{0}(1+R)\right)\right]}
\end{array} .
$$

Continuity thus implies that there exists $E[R]-\frac{\operatorname{Cov}\left(-R, u^{\prime}\left(w_{0}(1+R)\right)\right)}{E\left[u^{\prime}\left(w_{0}(1+R)\right)\right]}<\widehat{r_{f}}(k)<E[R]$ such that $\alpha_{k}^{*}=\alpha_{0}^{*}$. At $\widehat{r_{f}}(k)$ the following first order conditions

$$
\left.\frac{d E[u(w(\alpha))]}{d \alpha}\right|_{\alpha=\alpha_{0}^{*}}=E\left[w_{0}\left(R-\widehat{r_{f}}(k)\right) u^{\prime}\left(w\left(\alpha_{0}^{*}\right)\right)\right]=0
$$

and

$$
\left.\frac{d E\left[u_{k}(w(\alpha))\right]}{d \alpha}\right|_{\alpha=\alpha_{0}^{*}}=E\left[w_{0}\left(R-\widehat{r_{f}}(k)\right) u^{\prime}\left(w\left(\alpha_{0}^{*}\right)\right)\left(1+k g^{\prime}\left(u\left(w^{\max }\right)-u\left(w\left(\alpha_{0}^{*}\right)\right)\right)\right)\right]=0
$$

lead to the condition

$$
E\left[w_{0}\left(R-\widehat{r_{f}}(k)\right) u^{\prime}\left(w\left(\alpha_{0}^{*}\right)\right) g^{\prime}\left(u\left(w^{\max }\right)-u\left(w\left(\alpha_{0}^{*}\right)\right)\right)\right]=0 .
$$

As this condition is independent of $k$ we conclude that $\widehat{r_{f}}(k)=\widehat{r_{f}}$ for all $k \geq 0$.

In other words, for some intermediate risk premium, a regret-averse investor chooses a portfolio allocation as if he did not consider regret.

We summarize our findings in Figure 1.

Remark 5 We would like to point out that our results may help explain the equity premium puzzle as, at a high risk premiums, regret induces investors to select a less risky portfolio, as compared to investors who do not feel regret. 


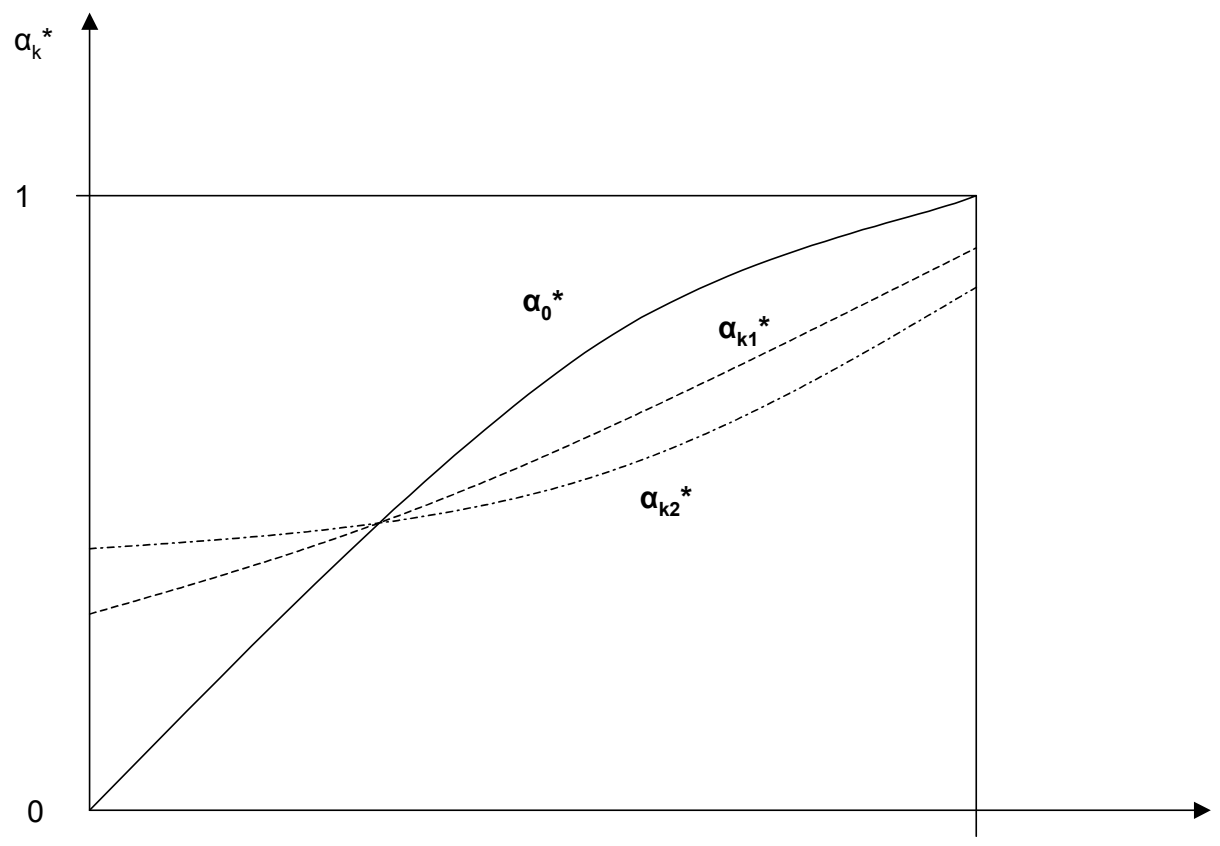

$E[R]-r_{f}$

Figure 1: Asset Allocation Without a Guarantee With a zero risk premium the risk-averse investor would invest all of his wealth in the risk-free asset $\left(\alpha_{0}^{*}=0\right)$. By contrast, the regret-averse investor would place some of his wealth in the stock $\left(\alpha_{k}^{*}>0\right)$. As the level of regret aversion rises, i.e. $k 2>k 1$, the amount of wealth invested in the stock increases. With a relatively large risk premium, the risk-averse investor allocates all of his wealth in stock $\left(\alpha_{0}^{*}=1\right)$, while the regret-averse investor invests some money in the risk-free asset $\left(\alpha_{k}^{*}<1\right)$. As the level of regret aversion increases, with a high risk premium, the amount of wealth invested in stock decreases. 


\section{The Impact of Guarantees on Portfolio Allocation}

We now assume that a guaranteed return on the risky asset is provided at zero cost to the investor. ${ }^{2}$ In this section, we show how the optimal asset allocation responds to the guarantee, for a risk-averse versus a regret-averse investor.

Let $r_{g} \geq-1$ be the guaranteed return on the risky asset. The return of this contingent contract is therefore $R_{g}=\max \left(R, r_{g}\right)$. To exclude statewise dominance of the guaranteed risky asset over the risk-free asset, we assume that $r_{g}<r_{f}$. The investor with regret parameter $k \geq 0$ selects a portfolio allocation $\alpha_{k}\left(r_{g}\right)$ to maximize his expected utility. Thus the optimal fraction $\alpha_{k}^{*}\left(r_{g}\right)$ invested in stocks solves the following problem

$$
\max _{\alpha \in[0,1]} E\left[u_{k}\left(w_{0}\left(1+\alpha R_{g}+(1-\alpha) r_{f}\right)\right)\right]
$$

where $u_{k}(w)=u(w)-k \cdot g\left(u\left(w^{\max }\right)-u(w)\right)$. The optimal fraction invested in stocks with no guarantee is thus $\alpha_{k}^{*}(-1)=\alpha_{k}^{*}$.

We note that the guarantee does not alter the ex-post optimal level of final wealth $w^{\max }$. The ex-post optimal decision is to invest all in the risky asset if its realized return is above the risk-free rate of return, and all in the risk-free asset if otherwise, i.e. $w^{\max }=w_{0}\left(1+\max \left(R, r_{f}\right)\right)$.

\subsection{Risk-Averse Investor}

Proposition $6 \alpha_{0}^{*}\left(r_{g}\right) \geq \alpha_{0}^{*}(-1)$ for all $-1<r_{g}<r_{f}$ where equality holds if and only if $\alpha_{0}^{*}(-1)=1$.

Proof. Let $w\left(r_{g}, \alpha\right)=w_{0}\left(1+\alpha R_{g}+(1-\alpha) r_{f}\right)$ denote the level of final wealth with a fraction $\alpha$ invested into the risky asset with guaranteed return $r_{g}$. Our benchmark of not having a guarantee therefore yields a level of final wealth $w(-1, \alpha)=w_{0}\left(1+\alpha R+(1-\alpha) r_{f}\right)$. Evaluating

\footnotetext{
${ }^{2}$ We recognize that there is a cost of providing such a guarantee (see Lachance and Mitchell 2003), and further the cost may rise if the investor is allowed to reoptimize his portfolio.
} 
the first derivative of expected utility with respect $\alpha$ at $\alpha_{0}^{*}(-1)$ yields

$$
\begin{aligned}
\left.\frac{d E\left[u_{0}\left(w\left(r_{g}, \alpha\right)\right)\right]}{d \alpha}\right|_{\alpha=\alpha_{0}^{*}(-1)}= & E\left[w_{0}\left(R_{g}-r_{f}\right) u^{\prime}\left(w\left(r_{g}, \alpha_{0}^{*}(-1)\right)\right)\right] \\
= & E\left[w_{0}\left(R-r_{f}\right) u^{\prime}\left(w\left(r_{g}, \alpha_{0}^{*}(-1)\right)\right)\right] \\
& +E\left[w_{0}\left(r_{g}-R\right)^{+} u^{\prime}\left(w\left(r_{g}, \alpha_{0}^{*}(-1)\right)\right)\right]
\end{aligned}
$$

as $R_{g}=R+\left(r_{g}-R\right)^{+}$. Further, for realizations $r$ of the risky asset with $r \geq r_{f}$ we have $R_{g}=R$ and thus $w\left(r_{g}, \alpha_{0}^{*}(-1)\right)=w\left(-1, \alpha_{0}^{*}(-1)\right)$. For realizations $r<r_{f}$ we have $w\left(r_{g}, \alpha_{0}^{*}(-1)\right)>$ $w\left(-1, \alpha_{0}^{*}(-1)\right)$ and therefore $\left(R-r_{f}\right) u^{\prime}\left(w\left(r_{g}, \alpha_{0}^{*}(-1)\right)\right)>\left(R-r_{f}\right) u^{\prime}\left(w\left(-1, \alpha_{0}^{*}(-1)\right)\right)$. Hence

$$
\begin{aligned}
\left.\frac{d E\left[u_{0}\left(w\left(r_{g}, \alpha\right)\right)\right]}{d \alpha}\right|_{\alpha=\alpha_{0}^{*}(-1)}> & E\left[w_{0}\left(R-r_{f}\right) u^{\prime}\left(w\left(-1, \alpha_{0}^{*}(-1)\right)\right)\right] \\
& +E\left[w_{0}\left(r_{g}-R\right)^{+} u^{\prime}\left(w\left(r_{g}, \alpha_{0}^{*}(-1)\right)\right)\right] \\
> & 0
\end{aligned}
$$

where the first part of the sum is zero because of the FOC (2) and the second part is positive. $\left.\frac{d E\left[u_{0}\left(w\left(r_{g}, \alpha\right)\right)\right]}{d \alpha}\right|_{\alpha=\alpha_{0}^{*}(-1)}>0$ then implies that $\alpha_{0}^{*}\left(r_{g}\right)>\alpha_{0}^{*}(-1)$ as long as $\alpha_{0}^{*}(-1)<1$. For $\alpha_{0}^{*}(-1)=1$ we get the corner solution $\alpha_{0}^{*}\left(r_{g}\right)=1$.

This shows that a risk-averse investor with a zero price guarantee generally follows a riskier investment strategy than without a guarantee.

\subsection{Regret-Averse Investor}

Proposition $7 \alpha_{k}^{*}\left(r_{g}\right) \geq \alpha_{k}^{*}(-1)$ for all $-1<r_{g}<r_{f}, k>0$ where equality holds if and only if $\alpha_{k}^{*}(-1)=1$.

Proof. Analogous to the proof above, we evaluate the first derivative of expected utility 
with respect $\alpha$ at $\alpha_{k}^{*}(-1)$ which leads to

$$
\begin{aligned}
& \left.\frac{d E\left[u_{k}\left(w\left(r_{g}, \alpha\right)\right)\right]}{d \alpha}\right|_{\alpha=\alpha_{k}^{*}(-1)} \\
= & E\left[w_{0}\left(R_{g}-r_{f}\right) u^{\prime}\left(w\left(r_{g}, \alpha_{k}^{*}(-1)\right)\right)\left(1+k g^{\prime}\left(u\left(w^{\max }\right)-u\left(w\left(r_{g}, \alpha_{k}^{*}(-1)\right)\right)\right)\right]\right. \\
= & E\left[w_{0}\left(R-r_{f}\right) u^{\prime}\left(w\left(r_{g}, \alpha_{k}^{*}(-1)\right)\right)\left(1+k g^{\prime}\left(u\left(w^{\max }\right)-u\left(w\left(r_{g}, \alpha_{k}^{*}(-1)\right)\right)\right)\right)\right] \\
& +E\left[w_{0}\left(r_{g}-R\right)^{+} u^{\prime}\left(w\left(r_{g}, \alpha_{k}^{*}(-1)\right)\right)\left(1+k g^{\prime}\left(u\left(w^{\max }\right)-u\left(w\left(r_{g}, \alpha_{k}^{*}(-1)\right)\right)\right)\right)\right] .
\end{aligned}
$$

For realizations $r$ of the risky asset with $r \geq r_{f}$ we have $R_{g}=R$ and thus $w\left(r_{g}, \alpha_{k}^{*}(-1)\right)=$ $w\left(-1, \alpha_{k}^{*}(-1)\right)$. For realizations $r<r_{f}$ we have $w\left(r_{g}, \alpha_{0}^{*}(-1)\right)>w\left(-1, \alpha_{0}^{*}(-1)\right)$ and therefore $u^{\prime}\left(w\left(r_{g}, \alpha_{k}^{*}(-1)\right)\right)<u^{\prime}\left(w\left(-1, \alpha_{k}^{*}(-1)\right)\right)$ and

$$
g^{\prime}\left(u\left(w^{\max }\right)-u\left(w\left(r_{g}, \alpha_{k}^{*}(-1)\right)\right)\right)<g^{\prime}\left(u\left(w^{\max }\right)-u\left(w\left(-1, \alpha_{k}^{*}(-1)\right)\right)\right) .
$$

Hence

$$
\begin{aligned}
& \left(R-r_{f}\right) u^{\prime}\left(w\left(r_{g}, \alpha_{k}^{*}(-1)\right)\right)\left(1+k g^{\prime}\left(u\left(w^{\max }\right)-u\left(w\left(r_{g}, \alpha_{k}^{*}(-1)\right)\right)\right)\right) \\
>\quad & \left(R-r_{f}\right) u^{\prime}\left(w\left(-1, \alpha_{k}^{*}(-1)\right)\right)\left(1+k g^{\prime}\left(u\left(w^{\max }\right)-u\left(w\left(-1, \alpha_{k}^{*}(-1)\right)\right)\right)\right)
\end{aligned}
$$

and thus

$$
\begin{aligned}
& \left.\frac{d E\left[u_{k}\left(w\left(r_{g}, \alpha\right)\right)\right]}{d \alpha}\right|_{\alpha=\alpha_{k}^{*}(-1)} \\
> & E\left[w\left(R-r_{f}\right) u^{\prime}\left(w\left(-1, \alpha_{k}^{*}(-1)\right)\right)\left(1+k g^{\prime}\left(u\left(w^{\max }\right)-u\left(w\left(-1, \alpha_{k}^{*}(-1)\right)\right)\right)\right)\right] \\
& +E\left[w_{0}\left(r_{g}-R\right)^{+} u^{\prime}\left(w\left(r_{g}, \alpha_{0}^{*}(-1)\right)\right)\left(1+k g^{\prime}\left(u\left(w^{\max }\right)-u\left(w\left(r_{g}, \alpha_{k}^{*}(-1)\right)\right)\right)\right)\right] \\
> & 0
\end{aligned}
$$

where the first part of the sum is zero because of the FOC (5) and the second part is positive. $\left.\frac{d E\left[u_{0}\left(w\left(r_{g}, \alpha\right)\right)\right]}{d \alpha}\right|_{\alpha=\alpha_{k}^{*}(-1)}>0$ then implies that $\alpha_{k}^{*}\left(r_{g}\right)>\alpha_{k}^{*}(-1)$ as long as $\alpha_{k}^{*}(-1)<1$. For $\alpha_{k}^{*}(-1)=1$ we get the corner solution $\alpha_{k}^{*}\left(r_{g}\right)=1$.

Analogous to the above, the regret-averse investor with a zero price guarantee invests a 
larger fraction of his wealth in stock than without a guarantee.

This proposition shows that a guarantee has an asymmetric impact on the effect of regret on portfolio allocation. At high risk premiums, the guarantee induces the regret-averse investor to move towards the extreme decision of investing all in stock. At low risk premiums, however, the guarantee induces the regret-averse investor to move further away from the extreme decision of investing all in the risk-free asset. Intuitively, this derives from the fact that a guaranteed rate of return provides a lower floor on the risky asset's return. The guarantee thus diminishes the disutility that results from regret the investor experiences at high risk premiums given low realizations of the risky asset's return. The regret-averse investor then invests more in the risky asset if he is endowed with the guarantee, and his portfolio allocation looks "more similar" to the one of a pure risk-averse investor. At low risk premiums, however, regret is derived mostly from high realizations of the risky-asset's return, and the guarantee has only a small impact on the disutility derived from regret. The regret-averse investor thus invests even more in the risky asset.

We summarize our results in Figure 2.

\section{Willingness To Pay for Return Guarantees}

In the previous section, guarantees were assumed to be offered at zero price, and investors were permitted to reallocate their portfolios accordingly. As we showed above, this will frequently induce the investor to hold more stocks in their pension portfolio which in turn increases the cost of providing such protection. In this section, we fix the investor's portfolio allocation to mitigate this moral hazard problem. Under this condition, we analyze the investor's WTP for the guarantee.

Let $P_{k}\left(r_{g}, \bar{\alpha}\right)$ denote the maximum price the investor with regret parameter $k \geq 0$ is willing to pay for the guaranteed return $r_{g}$ if his risky asset allocation is fixed at $\bar{\alpha}$. His 


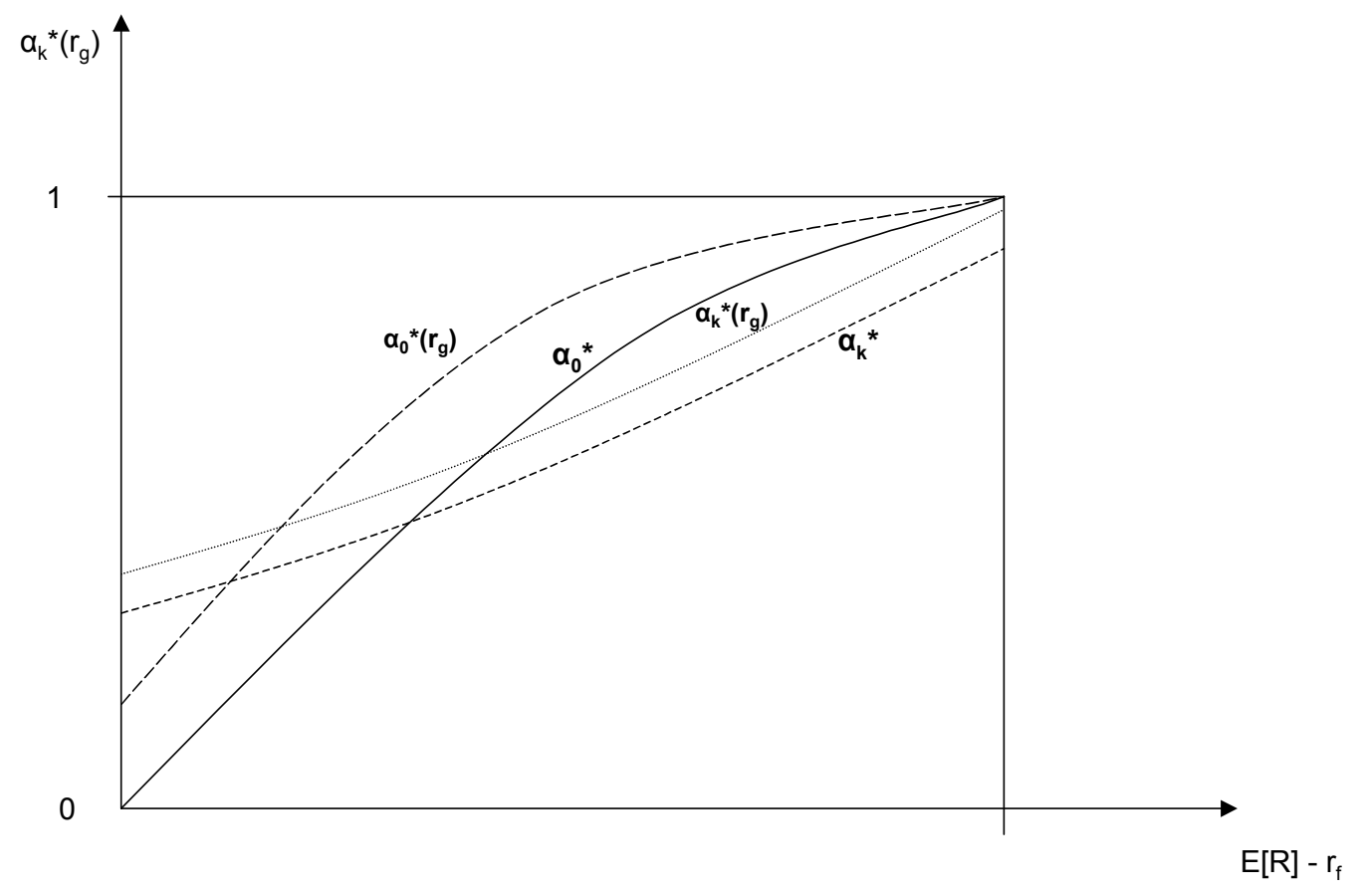

Figure 2: Asset Allocation With a Guarantee With a guarantee $\left(\alpha^{*}\left(r_{g}\right)\right)$ and zero risk premium, a riskaverse investor $(k=0)$ will invest more wealth into the stock $\left(\alpha_{0}^{*}\left(r_{g}\right)\right)$ and so will a regret-averse investor $\left(\alpha_{k}^{*}\left(r_{g}\right)\right)$. With a higher risk premium, the risk-averse investor will invest all his wealth into the stock with a guarantee and a regret-averse investor will increase his investment into the risky asset. Therefore, at a significantly high risk premium, with a guarantee on the risky asset, regret causes the investor to behave more like the risk-averse investor. 
WTP $P_{k}\left(r_{g}, \bar{\alpha}\right)$ is thus determined by

$$
E\left[u_{k}\left(\left(w_{0}\left(1+\bar{\alpha} R+(1-\bar{\alpha}) r_{f}\right)\right)\right)\right]=E\left[u_{k}\left(\left(w_{0}-P_{k}\left(r_{g}, \bar{\alpha}\right)\right)\left(1+\bar{\alpha} R_{g}+(1-\bar{\alpha}) r_{f}\right)\right)\right],
$$

i.e.

$$
E\left[u_{k}((w(-1, \bar{\alpha})))\right]=E\left[u_{k}\left(\frac{w_{0}-P_{k}\left(r_{g}, \bar{\alpha}\right)}{w_{0}} \cdot w\left(r_{g}, \bar{\alpha}\right)\right)\right]
$$

where $u_{k}(w)=u(w)-k \cdot g\left(u\left(w^{\max }\right)-u(w)\right)$ and $w\left(r_{g}, \alpha\right)=w_{0}\left(1+\alpha R_{g}+(1-\alpha) r_{f}\right)$.

Obviously, if no guarantee is provided $\left(r_{g}=-1\right)$ the investor's WTP is zero $\left(P_{k}(-1, \bar{\alpha})=0\right.$ for all $0 \leq \bar{\alpha} \leq 1)$. In addition, if the investor's wealth is fixed to be all in bonds, his WTP for the stock guarantee is zero $\left(P_{k}\left(r_{g}, 0\right)=0\right.$ for all $\left.-1 \leq r_{g} \leq r_{f}\right)$.

As mentioned before, the guarantee does not alter the ex-post optimal level of final wealth $w^{\max }$. Ex-post, therefore, it is always suboptimal to have bought a guaranteed rate of return. Ex-ante, one might nevertheless buy a guarantee to diminish the disutility derived from ex-post regret.

\subsection{Risk-Averse Investor}

The following proposition establishes comparative statics of the WTP with respect to the guaranteed return $r_{g}$ for the risk-averse investor.

Proposition $8 \frac{\partial P_{0}\left(r_{g}, \bar{\alpha}\right)}{\partial r_{g}}>0, \frac{\partial^{2} P_{0}\left(r_{g}, \bar{\alpha}\right)}{\partial r_{g}^{2}}<0$ for all $0<\bar{\alpha} \leq 1$. For $\bar{\alpha}=0, P\left(r_{g}, 0\right)=0$.

Proof. Differentiating (8) twice with respect to $r_{g}$ implies

$$
0=E\left[\left(\bar{\alpha} 1_{\left\{R<r_{g}\right\}}\left(w_{0}-P_{0}\left(r_{g}, \bar{\alpha}\right)\right)-\frac{\partial P_{0}\left(r_{g}, \bar{\alpha}\right)}{\partial r_{g}} \cdot \frac{w\left(r_{g}, \alpha\right)}{w_{0}}\right) \cdot u^{\prime}\left(\frac{w_{0}-P_{0}\left(r_{g}, \bar{\alpha}\right)}{w_{0}} \cdot w\left(r_{g}, \bar{\alpha}\right)\right)\right]
$$


and

$$
\begin{aligned}
0= & E\left[\left(\bar{\alpha} 1_{\left\{R<r_{g}\right\}}\left(w_{0}-P_{0}\left(r_{g}, \bar{\alpha}\right)\right)-\frac{\partial P_{0}\left(r_{g}, \bar{\alpha}\right)}{\partial r_{g}} \cdot \frac{w\left(r_{g}, \alpha\right)}{w_{0}}\right)^{2} \cdot u^{\prime \prime}\left(\frac{w_{0}-P_{0}\left(r_{g}, \bar{\alpha}\right)}{w_{0}} \cdot w\left(r_{g}, \bar{\alpha}\right)\right)\right. \\
& \left.-\left(\frac{\partial^{2} P_{0}\left(r_{g}, \bar{\alpha}\right)}{\partial r_{g}^{2}} \cdot \frac{w\left(r_{g}, \alpha\right)}{w_{0}}+2 \bar{\alpha} 1_{\left\{R<r_{g}\right\}} \frac{\partial P_{0}\left(r_{g}, \bar{\alpha}\right)}{\partial r_{g}}\right) \cdot u^{\prime}\left(\frac{w_{0}-P_{0}\left(r_{g}, \bar{\alpha}\right)}{w_{0}} \cdot w\left(r_{g}, \bar{\alpha}\right)\right)\right] .
\end{aligned}
$$

Solving for $\frac{\partial P_{0}\left(r_{g}, \bar{\alpha}\right)}{\partial r_{g}}$ and $\frac{\partial^{2} P_{0}\left(r_{g}, \bar{\alpha}\right)}{\partial r_{g}^{2}}$ leads to

$$
\frac{\partial P_{0}\left(r_{g}, \bar{\alpha}\right)}{\partial r_{g}}=\frac{E\left[\bar{\alpha} 1_{\left\{R<r_{g}\right\}}\left(w_{0}-P_{0}\left(r_{g}, \bar{\alpha}\right)\right) \cdot u^{\prime}\left(\frac{w_{0}-P_{0}\left(r_{g}, \bar{\alpha}\right)}{w_{0}} \cdot w\left(r_{g}, \bar{\alpha}\right)\right)\right]}{E\left[\frac{w\left(r_{g}, \alpha\right)}{w_{0}} \cdot u^{\prime}\left(\frac{w_{0}-P_{0}\left(r_{g}, \bar{\alpha}\right)}{w_{0}} \cdot w\left(r_{g}, \bar{\alpha}\right)\right)\right]}
$$

and

$$
\frac{\partial^{2} P_{0}\left(r_{g}, \bar{\alpha}\right)}{\partial r_{g}^{2}}=\frac{E\left[\begin{array}{c}
\left(\bar{\alpha} 1_{\left\{R<r_{g}\right\}}\left(w_{0}-P_{0}\left(r_{g}, \bar{\alpha}\right)\right)-\frac{\partial P_{0}\left(r_{g}, \bar{\alpha}\right)}{\partial r_{g}} \cdot \frac{w\left(r_{g}, \alpha\right)}{w_{0}}\right)^{2} \cdot u^{\prime \prime}\left(\frac{w_{0}-P_{0}\left(r_{g}, \bar{\alpha}\right)}{w_{0}} \cdot w\left(r_{g}, \bar{\alpha}\right)\right) \\
-2 \bar{\alpha} 1_{\left\{R<r_{g}\right\}} \frac{\partial P_{0}\left(r_{g}, \bar{\alpha}\right)}{\partial r_{g}} \cdot u^{\prime}\left(\frac{w_{0}-P_{0}\left(r_{g}, \bar{\alpha}\right)}{w_{0}} \cdot w\left(r_{g}, \bar{\alpha}\right)\right)
\end{array}\right]}{E\left[\frac{w\left(r_{g}, \alpha\right)}{w_{0}} \cdot u^{\prime}\left(\frac{w_{0}-P_{0}\left(r_{g}, \bar{\alpha}\right)}{w_{0}} \cdot w\left(r_{g}, \bar{\alpha}\right)\right)\right]} .
$$

This implies that the WTP $P_{0}\left(r_{g}, \bar{\alpha}\right)$ is increasing and concave in the fraction $\bar{\alpha}$ invested in the risky stock for all $0<\bar{\alpha} \leq 1$.

Two implications flow from this analysis. First, an investor holding some risky asset is willing to pay a strictly positive amount for a guarantee. In other words, since $P(-1, \bar{\alpha})=0$ (this represents no guarantee), then $\frac{\partial P_{0}\left(r_{g}, \bar{\alpha}\right)}{\partial r_{g}}>0$ implies $P_{0}\left(r_{g}, \bar{\alpha}\right)>0$ for all $0<\bar{\alpha} \leq 1$ and $-1<r_{g}<r_{f}$. This conforms with intuition, since risk-averse investors would be expected to want to pay something for lower variability in returns. For $\bar{\alpha}=0$, i.e. the investor holds only risk-free assets, his WTP for a guarantee is zero. Second, the WTP increases with the level of the guaranteed return $r_{g}$, but at a decreasing rate.

\subsection{Regret-Averse Investor}

Analogous to above, we derive the comparative statics of the WTP with respect to the 
guaranteed return $r_{g}$ for the regret-averse investor.

Proposition $9 \frac{\partial P_{k}\left(r_{g}, \bar{\alpha}\right)}{\partial r_{g}}>0, \frac{\partial^{2} P_{k}\left(r_{g}, \bar{\alpha}\right)}{\partial r_{g}^{2}}<0$ for all $0<\bar{\alpha} \leq 1, k \geq 0$. For $\bar{\alpha}=0$, $P_{k}\left(r_{g}, 0\right)=0$ for all $k \geq 0$.

Proof. Differentiating (8) twice with respect to $r_{g}$ implies

$$
\begin{aligned}
0= & E\left[\left(\bar{\alpha} 1_{\left\{R<r_{g}\right\}}\left(w_{0}-P_{k}\left(r_{g}, \bar{\alpha}\right)\right)-\frac{\partial P_{k}\left(r_{g}, \bar{\alpha}\right)}{\partial r_{g}} \cdot \frac{w\left(r_{g}, \alpha\right)}{w_{0}}\right) \cdot u^{\prime}\left(\frac{w_{0}-P_{k}\left(r_{g}, \bar{\alpha}\right)}{w_{0}} \cdot w\left(r_{g}, \bar{\alpha}\right)\right)\right. \\
& \left.\cdot\left(1+k g^{\prime}\left(u\left(w^{\max }\right)-u\left(\frac{w_{0}-P_{k}\left(r_{g}, \bar{\alpha}\right)}{w_{0}} \cdot w\left(r_{g}, \bar{\alpha}\right)\right)\right)\right)\right]
\end{aligned}
$$

and

$$
\begin{aligned}
0= & E\left[\left(\bar{\alpha} 1_{\left\{R<r_{g}\right\}}\left(w_{0}-P_{k}\left(r_{g}, \bar{\alpha}\right)\right)-\frac{\partial P_{k}\left(r_{g}, \bar{\alpha}\right)}{\partial r_{g}} \cdot \frac{w\left(r_{g}, \alpha\right)}{w_{0}}\right)^{2} \cdot u^{\prime \prime}\left(\frac{w_{0}-P_{k}\left(r_{g}, \bar{\alpha}\right)}{w_{0}} \cdot w\left(r_{g}, \bar{\alpha}\right)\right)\right. \\
& \cdot\left(1+k g^{\prime}\left(u\left(w^{\max }\right)-u\left(\frac{w_{0}-P_{k}\left(r_{g}, \bar{\alpha}\right)}{w_{0}} \cdot w\left(r_{g}, \bar{\alpha}\right)\right)\right)\right) \\
& -\left(\bar{\alpha} 1_{\left\{R<r_{g}\right\}}\left(w_{0}-P_{k}\left(r_{g}, \bar{\alpha}\right)\right)-\frac{\partial P_{k}\left(r_{g}, \bar{\alpha}\right)}{\partial r_{g}} \cdot \frac{w\left(r_{g}, \alpha\right)}{w_{0}}\right)^{2} \cdot u^{\prime}\left(\frac{w_{0}-P_{k}\left(r_{g}, \bar{\alpha}\right)}{w_{0}} \cdot w\left(r_{g}, \bar{\alpha}\right)\right) \\
& \cdot k g^{\prime \prime}\left(u\left(w^{\max }\right)-u\left(u\left(w^{\max }\right)-u\left(\frac{w_{0}-P_{k}\left(r_{g}, \bar{\alpha}\right)}{w_{0}} \cdot w\left(r_{g}, \bar{\alpha}\right)\right)\right)\right) \\
& -\left(\frac{\partial^{2} P_{k}\left(r_{g}, \bar{\alpha}\right)}{\partial r_{g}^{2}} \cdot \frac{w\left(r_{g}, \alpha\right)}{w_{0}}+2 \bar{\alpha} 1_{\left\{R<r_{g}\right\}} \frac{\partial P_{k}\left(r_{g}, \bar{\alpha}\right)}{\partial r_{g}}\right) \cdot u^{\prime}\left(\frac{w_{0}-P_{k}\left(r_{g}, \bar{\alpha}\right)}{w_{0}} \cdot w\left(r_{g}, \bar{\alpha}\right)\right) \\
& \cdot\left(1+k g^{\prime}\left(u\left(w^{\max }\right)-u\left(u\left(w^{\max }\right)-u\left(\frac{w_{0}-P_{k}\left(r_{g}, \bar{\alpha}\right)}{w_{0}} \cdot w\left(r_{g}, \bar{\alpha}\right)\right)\right)\right)\right] \cdot
\end{aligned}
$$

Solving for $\frac{\partial P_{k}\left(r_{g}, \bar{\alpha}\right)}{\partial r_{g}}$ and $\frac{\partial^{2} P_{k}\left(r_{g}, \bar{\alpha}\right)}{\partial r_{g}^{2}}$ leads to

$$
\frac{\partial P_{k}\left(r_{g}, \bar{\alpha}\right)}{\partial r_{g}}=\frac{E\left[\bar{\alpha} 1_{\left\{R<r_{g}\right\}}\left(w_{0}-P_{k}\left(r_{g}, \bar{\alpha}\right)\right) \cdot u^{\prime}\left(\frac{w_{0}-P_{k}\left(r_{g}, \bar{\alpha}\right)}{w_{0}} \cdot w\left(r_{g}, \bar{\alpha}\right)\right)\left(1+k g^{\prime}(\cdot)\right)\right]}{E\left[\frac{w\left(r_{g}, \alpha\right)}{w_{0}} \cdot u^{\prime}\left(\frac{w_{0}-P_{k}\left(r_{g}, \bar{\alpha}\right)}{w_{0}} \cdot w\left(r_{g}, \bar{\alpha}\right)\right)\left(1+k g^{\prime}(\cdot)\right)\right]}
$$


and

$$
\begin{aligned}
& 0=E\left[\left(\bar{\alpha} 1_{\left\{R<r_{g}\right\}}\left(w_{0}-P_{k}\left(r_{g}, \bar{\alpha}\right)\right)-\frac{\partial P_{k}\left(r_{g}, \bar{\alpha}\right)}{\partial r_{g}} \cdot \frac{w\left(r_{g}, \alpha\right)}{w_{0}}\right)^{2} \cdot u^{\prime \prime}\left(\frac{w_{0}-P_{k}\left(r_{g}, \bar{\alpha}\right)}{w_{0}} \cdot w\left(r_{g}, \bar{\alpha}\right)\right)\right. \\
& \cdot\left(1+k g^{\prime}\left(u\left(w^{\max }\right)-u\left(\frac{w_{0}-P_{k}\left(r_{g}, \bar{\alpha}\right)}{w_{0}} \cdot w\left(r_{g}, \bar{\alpha}\right)\right)\right)\right) \\
& -\left(\bar{\alpha} 1_{\left\{R<r_{g}\right\}}\left(w_{0}-P_{k}\left(r_{g}, \bar{\alpha}\right)\right)-\frac{\partial P_{k}\left(r_{g}, \bar{\alpha}\right)}{\partial r_{g}} \cdot \frac{w\left(r_{g}, \alpha\right)}{w_{0}}\right)^{2} \cdot u^{\prime}\left(\frac{w_{0}-P_{k}\left(r_{g}, \bar{\alpha}\right)}{w_{0}} \cdot w\left(r_{g}, \bar{\alpha}\right)\right) \\
& \cdot k g^{\prime \prime}\left(u\left(w^{\max }\right)-u\left(u\left(w^{\max }\right)-u\left(\frac{w_{0}-P_{k}\left(r_{g}, \bar{\alpha}\right)}{w_{0}} \cdot w\left(r_{g}, \bar{\alpha}\right)\right)\right)\right) \\
& -\left(\frac{\partial^{2} P_{k}\left(r_{g}, \bar{\alpha}\right)}{\partial r_{g}^{2}} \cdot \frac{w\left(r_{g}, \alpha\right)}{w_{0}}+2 \bar{\alpha} 1_{\left\{R<r_{g}\right\}} \frac{\partial P_{k}\left(r_{g}, \bar{\alpha}\right)}{\partial r_{g}}\right) \cdot u^{\prime}\left(\frac{w_{0}-P_{k}\left(r_{g}, \bar{\alpha}\right)}{w_{0}} \cdot w\left(r_{g}, \bar{\alpha}\right)\right) \\
& \left.\cdot\left(1+k g^{\prime}\left(u\left(w^{\max }\right)-u\left(u\left(w^{\max }\right)-u\left(\frac{w_{0}-P_{k}\left(r_{g}, \bar{\alpha}\right)}{w_{0}} \cdot w\left(r_{g}, \bar{\alpha}\right)\right)\right)\right)\right)\right] . \\
& \frac{\partial^{2} P_{k}\left(r_{g}, \bar{\alpha}\right)}{\partial r_{g}^{2}}=\frac{E\left[\begin{array}{c}
\left(\bar{\alpha} 1_{\left\{R<r_{g}\right\}}\left(w_{0}-P_{k}\left(r_{g}, \bar{\alpha}\right)\right)-\frac{\partial P_{k}\left(r_{g}, \bar{\alpha}\right)}{\partial r_{g}} \cdot \frac{w\left(r_{g}, \alpha\right)}{w_{0}}\right)^{2}\left(u^{\prime \prime}(\cdot)\left(1+k g^{\prime}(\cdot)\right)-u^{\prime}(\cdot) k g^{\prime \prime}(\cdot)\right) \\
-2 \bar{\alpha} 1_{\left\{R<r_{g}\right\}} \frac{\partial P_{k}\left(r_{g}, \bar{\alpha}\right)}{\partial r_{g}} u^{\prime}(\cdot)\left(1+k g^{\prime}(\cdot)\right)
\end{array}\right]}{E\left[\frac{w\left(r_{g}, \alpha\right)}{w_{0}} u^{\prime}\left(\frac{w_{0}-P_{k}\left(r_{g}, \bar{\alpha}\right)}{w_{0}} \cdot w\left(r_{g}, \bar{\alpha}\right)\right)\left(1+k g^{\prime}(\cdot)\right)\right]}
\end{aligned}
$$

Just as before, with the risk-averse investor, the regret-averse investor's WTP $P_{k}\left(r_{g}, \bar{\alpha}\right)$ is increasing and concave in the fraction $\bar{\alpha}$ invested in the risky stock for all $0<\bar{\alpha} \leq 1$. For $\bar{\alpha}=0$ his $\mathrm{WTP}$ is zero.

As before, a regret-averse investor holding some risky asset is willing to pay a strictly positive amount for a guarantee, even though it is never optimal ex-post to have bought the guarantee.

\section{Conclusions and Future Research}

This paper explores how the consideration of regret influences investors' portfolio allocation in a PRA. We also examine how participant portfolio choices would change if a rate of return guarantee on risky assets were provided at zero cost. Finally, we assess how much investors might be willing to pay for such a guarantee for a fixed portfolio allocation.

Our results show that, without a guarantee, regret moves investors' decisions away from 
the extremes. That is, investors who take regret into account hold more stock if the risk premium is low, but less stock if the risk premium is high. This result may explain the equity premium puzzle. Further, a rate of return guarantee provided at no cost to the plan participant induces him to hold more stock, with or without regret. At high risk premiums, the guarantee therefore induces decisions by regret-averse investors that are close to the ones of risk-averse investors. On the contrary, at low risk premiums, guarantees move regretaverse investors even further away from investing all in bonds. We also show that, with or without regret, investors' WTP for a guarantee rises with the level of the guaranteed return.

Extensions of this research would likely be fruitful. For example, we have assumed that the guarantee is written on the portion of the portfolio invested in risky assets. Nevertheless, in the real world, the guarantee might cover returns on the entire PRA portfolio, which in our case would likely reduce the cost of the guarantee. Exactly how much people would be willing to pay in this case could be examined in further analysis. We also would like to investigate what happens if the fraction of the PRA invested in risky asset cannot be fixed ex-ante. In this case, it would be of interest to ask whether there is an incentive-compatible contract which would still permit an attractive guarantee without being prohibitively expensive. Finally, it would be useful to ascertain whether financial intermediaries would find it profitable to enter into the guaranteed pension business, or how much the government would have to subsidize purchasers, so as to bring these products to market. 


\section{References}

[1] Agnew, Julie, Pierluigi Balduzzi, and Annika Sunden. "Portfolio Choice and Trading in a Large 401k Plan". American Economic Review 2003, pp. 193-215.

[2] Ameriks, John and Stephen Zeldes. "How Do Household Portfolio Shares Vary With Age?". TIAA-CREF Working Paper, 2000.

[3] Bodie, Zvi. "On the Risk of Stocks in the Long Run". Financial Analysts Journal, May/June 1995, pp. 18-22.

[4] Bodie, Zvi and Robert Merton. "Pension Benefit Guarantees in the United States: A Functional Analysis". In The Future of Pensions in the United States. Ed. R. Schmitt. University of Pennsylvania Press, 1993.

[5] Braun, Michael and Alexander Muermann. "The Impact of Regret on the Demand for Insurance". Working Paper. The Wharton School, University of Pennsylvania 2003.

[6] Cogan, John F. and Olivia S. Mitchell. "The Role of Economic Policy in Social Security Reform: Perspectives from the President's Commission." Journal of Economic Perspectives. 17(2). Spring 2003.

[7] Commission to Strengthen Social Security. Strengthening Social Security and Creating Personal Wealth for All Americans, 2001. www.ssa.gov.

[8] Feldstein, Martin and Elena Ranguelova. "Accumulated Pension Collars: A Market Approach to Reducing the Risk of Investment-Based Social Security Reform" in James Poterba, ed, Tax Policy and the Economy, Cambridge: MIT Press, 2001, pp.146-166.

[9] Fischer, Klaus P. "Pricing Pension Fund Guarantees: A Discrete Martingale Approach". Canadian Journal of Administrative Sciences, 1999, 16(3), pp. 256-266.

[10] Gollier, Christian. The Economics of Risk and Time. Cambridge, MA: MIT Press. 2001.

[11] Lachance, Marie-Eve, Olivia S. Mitchell, \& Kent Smetters. "Guaranteeing Defined Contribution Pensions: The Option to Buy Back a Defined Benefit Promise". Journal of Risk and Insurance. 70(1) 2003: 1-16. 
[12] Lachance, Marie-Eve and Olivia S. Mitchell. "Understanding Individual Account Guarantees," American Economic Review Papers and Proceedings May 2003. 93(2): 257260.

[13] Lachance, Marie-Eve and Olivia S. Mitchell. "Understanding Individual Account Guarantees." In Olivia S. Mitchell and Kent Smetters, eds. The Pension Challenge: Risk Transfers and Retirement Income Security. Pension Research Council. Oxford, UK: Oxford University Press, forthcoming.

[14] Maurer, Raimond and Christian Schlag, "Money-Back Guarantees in Individual Account Pensions: Evidence from the German Pension Reform." In Olivia S. Mitchell and Kent Smetters, eds. The Pension Challenge: Risk Transfers and Retirement Income Security. Pension Research Council. Oxford, UK: Oxford University Press, forthcoming.

[15] Mitchell, Olivia S. and Kent Smetters, eds. The Pension Challenge: Risk Management and Retirement Income Security. Pension Research Council, The Wharton School. Philadelphia: Forthcoming.

[16] Palacios, Robert. "Securing Public Pension Promises through Funding." In Olivia S. Mitchell and Kent Smetters, eds. The Pension Challenge: Risk Transfers and Retirement Income Security. Pension Research Council. Oxford, UK: Oxford University Press, forthcoming.

[17] Pennachi, George G. "The Value of Guarantees on Pension Fund Conversion." Journal of Risk and Insurance, 1999, 66(2), pp. 219-237.

[18] Smetters, Kent. "Controlling the Costs of Minimum Benefit Guarantees in Public Pension Conversions." Journal of Pension Economics and Finance, 1(1), March 2002, pp. $9-34$.

[19] Turner, John and David Rajnes. "Retirement Guarantees in Voluntary Defined Contribution Plans." In Olivia S. Mitchell and Kent Smetters, eds. The Pension Challenge: Risk Transfers and Retirement Income Security . Pension Research Council. Oxford, UK: Oxford University Press, forthcoming.

[20] Walliser, Jan. "Retirement Guarantees in Mandatory Defined Contribution Systems" 
In Olivia S. Mitchell and Kent Smetters, eds. The Pension Challenge: Risk Transfers and Retirement Income Security. Pension Research Council. Oxford, UK: Oxford University Press, forthcoming. 